\title{
DEGREASING PROCESS CONTROL IN AUTOMOTIVE INDUSTRY
}

\author{
${ }^{1}$ Michael TROMBIK, ${ }^{2}$ Petr MOHYLA \\ ${ }^{1} H M M C$ - Hyundai Motor Manufacturing Czech, Nošovice, Czech Republic, EU, \\ michael.trombik@hyundai-motor.cz \\ ${ }^{2}$ VSB - Technical University of Ostrava, Ostrava, Czech Republic, EU, \\ petr.mohyla@vsb.cz
}

https://doi.org/10.37904/metal.2019.775

\begin{abstract}
The main topic is to find energy cost saving item and implementation method in the pretreatment process at the paint production plant. The paper presents explanation of experiment with temperature reduction and its influence on the quality and steam consumption. By reduction of the temperature by $3{ }^{\circ} \mathrm{C}$ we can save $10 \%$ of steam. During experiment it was found an alternative source of heat for the degreasing process, in the form of recuperation waste heat from the oven.
\end{abstract}

Keywords: Degreasing, cost saving, steel, paint, steam, implementation

\section{INTRODUCTION}

The automotive industry is one of the biggest and complex businesses, which covers various fields of industry. Each process of the company must be controlled efficiently with the lowest possible costs. In this article, we will focus at energy cost saving at the degreasing process by steam and influence on the quality and chemical consumption. The main result will be the implementation process for production. A secondary goal is to find an alternative heating method.

Technological and process improvements in automotive is mostly hidden from public, due sensitive material and possibility of use information's by competitors. This is main reason, why is almost impossible to find information which will be suitable for application in pretreatment. Each manufacturer is using some different equipment, chemicals and process. Hyundai Motor Group is having more than 17 factories and each is different. Process engineers have to make own studies and try to find better solutions.

This article will consider only facilities for full paint body production. Not for separated parts, like bumpers, which is manufactured by suppliers.

\subsection{Paint layers}

Carmakers are using several possible methods of paint structure and application methods. Most common is using 4 paint layers (see Figure 1). Each layer must be baked in the oven at the specific baking window, which can be various, according to material supplier.

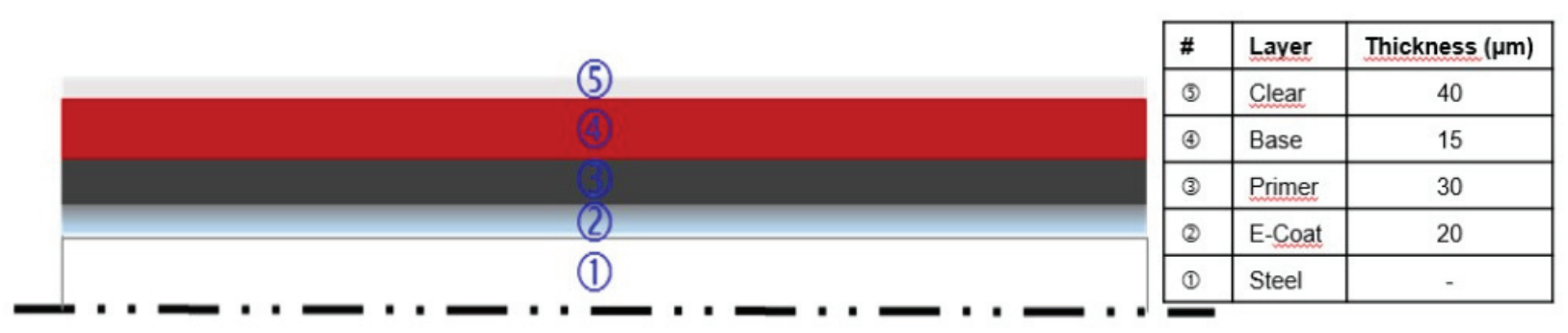

Figure 1 Paint layers 


\section{DEGREASING PROCESS}

Degreasing is the first process after receiving a body from the welding shop. The main function is to remove oil, metal dust, impurities from the previous process and prepare the surface, for paint application. During passing of the body, must be maintained proper production temperature by steam. Steam as heating source, is used on 5 stages. Details of the researched degreasing process are visible in Table 1.

Table 1 Degreasing process overview

\begin{tabular}{|c|c|c|c|}
\hline Process & Function & Method & Heating \\
\hline Pre-hot water rinse & Pre-rinsing & Spray & Steam \\
\hline Hot water rinse & Remove metal dust & Dip & Steam \\
\hline Pre-Degrease & Remove oil and grease & Dip & Steam \\
\hline Degrease & Remove oil, grease, dust & Spray & - \\
\hline Rinse 1 & Substrate cleaning & Dip & Steam \\
\hline Rinse 2 & Substrate cleaning & Dip & - \\
\hline Activation & Surface treatment & Spray & - \\
\hline Phosphate & Apply phosphate layer & Dip & - \\
\hline Rinse 3 & Cleaning & Spray & - \\
\hline Rinse 4 & Cleaning & Dip + spray & \\
\hline Rinse 5 & Cleaning & & \\
\hline Final Rinse & & & \\
\hline
\end{tabular}

\subsection{Overview of current progress in the field}

The final surface properties of steel products depend on different processing conditions such as changes in alloy elements, different annealing temperatures, rolling parameters and surface chemicals used in the degreasing process. These changes in process parameters affect the surface roughness, surface oxide formation and structure. Quality depends on the degreasing parameters (immersion time, bath temperature, chemical concentration) [1]. Currently is visible also some new method for evaluation of surface quality for example by UV-Vis spectroscopy. According result of authors this method is still in development [2].

As interesting idea is US patent US20170211188A1, based on chemical conversion, without high demands on energy consumption. But still lot of parts at cars is not following required alloy composition. Car manufactures are still using two degreasing agents and heating of baths [3].

\subsection{Energy consumption}

Source of heating is direct steam feeding with a range of temperature between $145-176{ }^{\circ} \mathrm{C}$. The purpose of the heating system is to heat the bath solution to a pre-set temperature $49-55^{\circ} \mathrm{C}$. Heating is affected by feeding saturated steam from the supply net, directly into process tank, so that circulated process bath is mixed with steam. Temperature is measured by resistance thermometer, with its sensor being located in the circulation pipe, on the suction side of the pump. Heated stages layout of the researched degreasing process is visible in Figure 2.

The process is connected to control system and temperature can be adjusted. Fluctuation from $51{ }^{\circ} \mathrm{C}$ to $53.6^{\circ} \mathrm{C}$ was detected during observing the temperature historical trend (see Figure 3). This $2.6^{\circ} \mathrm{C}$ difference gives question, if we can reduce the temperature more. 


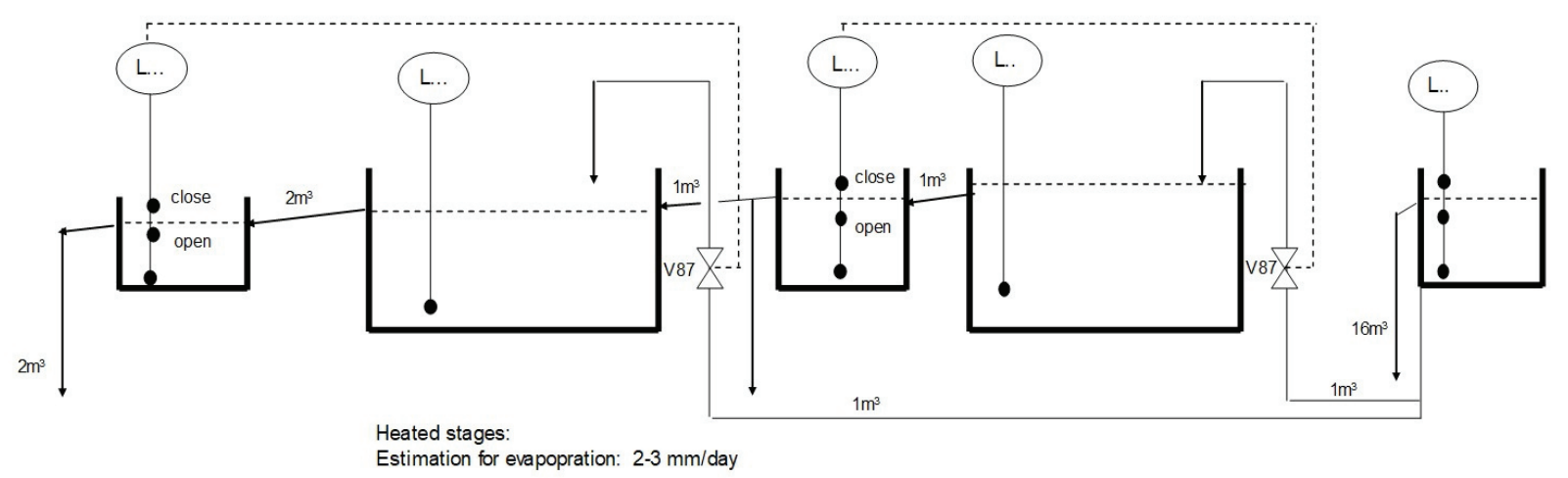

Figure 2 Degreasing layout [4]

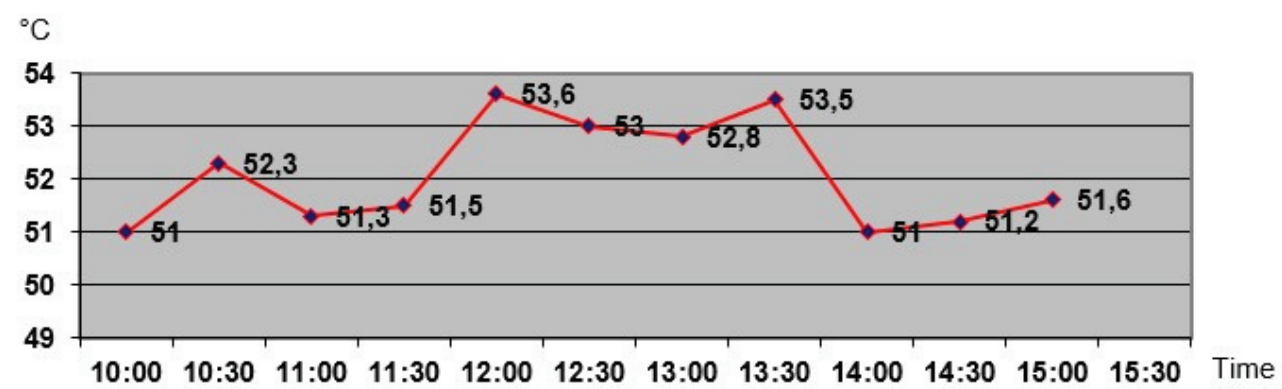

Figure 3 Pre-degrease temperature trend

\section{EXPERIMENTAL PART}

\subsection{Energy cost saving method}

For proper and secure implementation of cost-saving improvement is recommended to prepare [5]:

1) Compile business expense statements - identification of operating expenses and gathering information required for cost reduction analysis.

2) Analyze operating expenses - to maximize saving, analyze all aspects of business overhead, including manpower, technology condition, automatization, maintenance, work standards and more.

3) Present identified cost saving and expense reduction recommendations - after finding cost saving, present to management and all related departments in order to receive approval for the next step.

4) Implement cost saving recommendations - prepare testing plan, try-out, implementation to production and investment budget if necessary.

Main goal is to find cost saving in current degreasing process without much additional cost. Pay-back must be lower than 1 year. Due this fact it is very hard to find some ideas and possibilities for real implementation in production.

\subsection{Quality test}

Change of temperature can have the biggest influence on degreasing capability and amount of oils in the bath.

Weekend test on contaminated panels was selected to verify degreasing capability. Original line setting is $55^{\circ} \mathrm{C}$. For first test, it was used $53{ }^{\circ} \mathrm{C}$, second $51{ }^{\circ} \mathrm{C}$ and last $49{ }^{\circ} \mathrm{C}$. On testing panels (see Figure 4), it is visible $\mathrm{OK}$ result for $51^{\circ} \mathrm{C}$ and not good for $49^{\circ} \mathrm{C}$. Now we have a range in which we can adjust the line. 

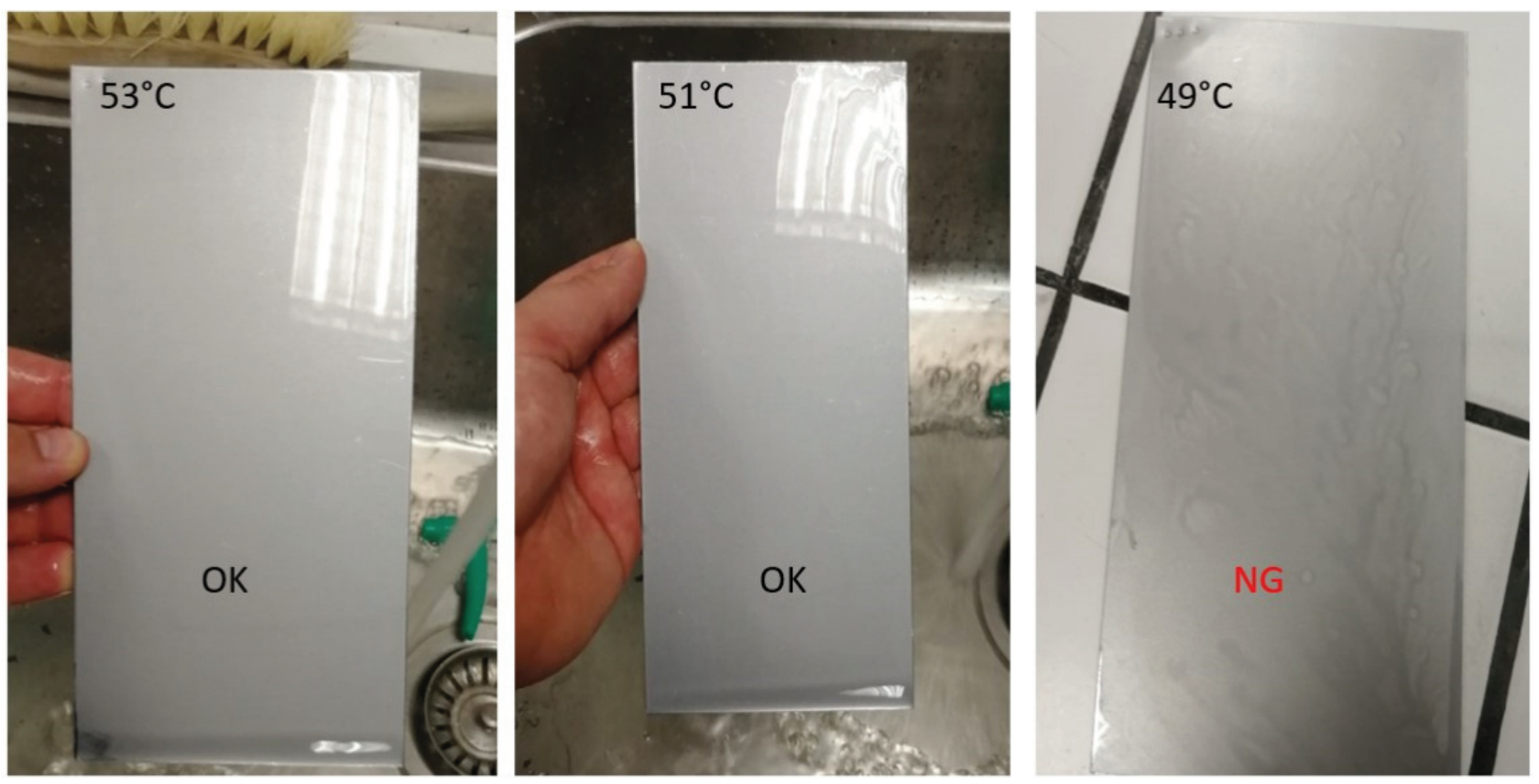

Figure 4 Degreasing test

Bath sample was taken to verify the oil amount. Oils maximum limit is $3,000 \mathrm{ppm}$ in the bath. A result from laboratory measurement for $49^{\circ} \mathrm{C}$ bath temperature was $1,480 \mathrm{ppm}$ (see details in Table 2).

Table 2 Degrease analysis

\begin{tabular}{|c|c|c|c|c|c|}
\hline Item & Range & Original & Test $53{ }^{\circ} \mathrm{C}$ & Test $51^{\circ} \mathrm{C}$ & Test $49^{\circ} \mathrm{C}$ \\
\hline Total alcality & $19-21$ & 18.5 & 18.5 & 18.9 & $\mathbf{1 9 . 3}$ \\
\hline $\mathrm{pH}$ & $>9.5$ & 10.4 & 9.9 & 10.7 & $\mathbf{1 1}$ \\
\hline Oil [ppm] & max. 3,000 & 1,200 & 1,240 & 1,400 & $\mathbf{1 , 4 8 0}$ \\
\hline
\end{tabular}

From the degreasing test and analysis, we can expect safe temperature window between $55^{\circ} \mathrm{C}$ and $51{ }^{\circ} \mathrm{C}$.

\subsection{Implementation of cost saving}

Before the implementation of cost improvement, it is necessary to confirm the influence on quality by 1 hour line test with $52{ }^{\circ} \mathrm{C}$ temperature. During test it was monitored the visual appearance of the surface, oil amount in a dip tank, steam consumption and adhesion grid test. The target for appearance is no oil marks, welding dust and a proper amount of phosphate layer. The test must be monitored until the application of a clear coat layer (final layer).

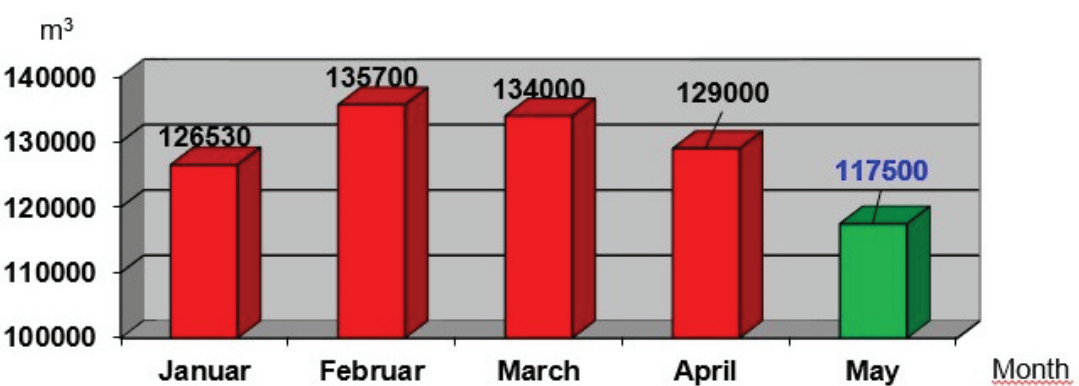

Figure 5 Steam consumption trend 
For monitoring of consumption was used Proline Prowirl F200 Vortex flowmeter, which was installed for all stages. According result from May (see Figure 5), we can see reduction of steam consumption by $10 \%$.

All monitored values are in specification. Steam consumption decreased by $10 \%$. Due to the good result, it was decided to implement a new setting permanently with higher priority to monitor any changes.

\section{CONCLUSION}

After implementation temperature adjusting in degreasing process from $55^{\circ} \mathrm{C}$ to $52{ }^{\circ} \mathrm{C}$ it was reached $10 \%$ cost saving in steam consumption, confirmed by data from steam flowmeter. Obtained result was without influence on quality and dosing of cleaning chemicals. At least 2 times per year it is necessary to check and evaluate each line parameters. Some technical sets are from the beginning of plant building without adjusting. In the current market situation, it is required to evaluate all aspects of energy consumption and adjust them if possible. Big advantage of this solution is no requirement for investment cost, basically, only a change of number can have a big influence on the money.

A secondary goal for cost saving is finding an alternative source of heating. A requirement for energy heating is $145-176{ }^{\circ} \mathrm{C}$ or $2,000 \mathrm{~kW}$, the pipe diameter is DN 200 . Biggest energy consumption in the paint shop has an oven. During analysis, was detected and prepared project for re-using of oven exhaust heat to pretreatment process. One oven is creating waste heat by $200^{\circ} \mathrm{C}$, with pipe DN 400 , which is possible to use. Pay-back of this investment project is 2 years. Details will be described in the next article. Similar solution was used at tomato processing factory in California in the United States. By reusing of waste heat is possible to save approximately $7.3 \mathrm{GWh}$ of energy [6].

\section{REFERENCES}

[1] ÇALIŞKAN, Emel, et al. Characteristics of Surface Properties of Aluminum Flat Products Related with Different Annealing Temperature and Cleaning Properties. In: Light Metals 2019. Cham: Springer, 2019. pp. 323-329.

[2] ZOUBEK, Michal, et al. Complex control method of degreasing process. In: Advances in Manufacturing. Springer, Cham, 2018. pp. 575-585.

[3] Method for Treating Surface of Zinc-Alumnum-Magnesum Alloy Plated Steel, Sheet. 2017. US 2017/0211188 A1. Created Jul. 27, 2017. Available from:

https://patentimages.storage.googleapis.com/3d/ff/7b/989faeb2efc0c7/US20170211188A1.pdf.

[4] Technical Documentation / Operating Instructions Pretreatment System. Ostrava, Czech, 2007.

[5] SIMPLE BUSINESS SOLUTION. Cost Reduction Analysis. [online]. Simple Business Solution-Redding, @2019. [viewed 2019-04-30]. Available from: http://www.cutcostsgrowsales.com/services/cost-reduction.

[6] AMÓN, Ricardo, et al. Waste heat and water recovery opportunities in California tomato paste processing. Applied Thermal Engineering. 2015, vol. 78, pp. 525-532. 